\title{
TU/e EN⿴HONE

\section{Estimation of the band broadening contribution of HPLC equipment to column elution profiles}

\section{Citation for published version (APA):}

Claessens, H. A., Cramers, C. A. M. G., \& Kuyken, M. A. J. (1987). Estimation of the band broadening contribution of HPLC equipment to column elution profiles. Chromatographia, 23(3), 189-194.

https://doi.org/10.1007/BF02311478

DOI:

10.1007/BF02311478

Document status and date:

Published: 01/01/1987

\section{Document Version:}

Publisher's PDF, also known as Version of Record (includes final page, issue and volume numbers)

\section{Please check the document version of this publication:}

- A submitted manuscript is the version of the article upon submission and before peer-review. There can be important differences between the submitted version and the official published version of record. People interested in the research are advised to contact the author for the final version of the publication, or visit the $\mathrm{DOI}$ to the publisher's website.

- The final author version and the galley proof are versions of the publication after peer review.

- The final published version features the final layout of the paper including the volume, issue and page numbers.

Link to publication

\section{General rights}

Copyright and moral rights for the publications made accessible in the public portal are retained by the authors and/or other copyright owners and it is a condition of accessing publications that users recognise and abide by the legal requirements associated with these rights.

- Users may download and print one copy of any publication from the public portal for the purpose of private study or research.

- You may not further distribute the material or use it for any profit-making activity or commercial gain

- You may freely distribute the URL identifying the publication in the public portal.

If the publication is distributed under the terms of Article 25fa of the Dutch Copyright Act, indicated by the "Taverne" license above, please follow below link for the End User Agreement:

www.tue.nl/taverne

Take down policy

If you believe that this document breaches copyright please contact us at:

openaccess@tue.nl

providing details and we will investigate your claim. 


\title{
Estimation of the Band Broadening Contribution of HPLC Equipment to Column Elution Profiles
}

\author{
H. A. Claessens* / C. A. Cramers \\ Laboratory of Instrumental Analysis, Eindhoven University of Technology, P. O. Box 513, 5600 MB Eindhoven, \\ The Netherlands
}

\author{
M. A. J. Kuyken \\ N. V. Philips, Central Laboratory Elcoma, P. O. Box 218, 5600 MD Eindhoven, The Netherlands
}

\section{Key Words}

Column liquid chromatography

Instrument bandbroadening by extrapolation

\section{Summary}

Methods to determine the contribution of the chromatographic equipment to the total band broadening which involve replacing the column by a union or a capillary tube are not suitable as they involve a fundamental change in the chromatographic system.

The linear extrapolation method, based on the estimation of the relative influence of the instrument variance on solutes with different capacity factors, is a more attractive alternative method since the column remains in the chromatographic system.

This method is only valid when a number of conditions are satisfied. By meeting these conditions the error in the instrument variance by using the linear extrapolation method was determined. At the same time, ways to minimise these errors were studied.

Use of the linear extrapolation method in combination with conventional columns of $4.6 \mathrm{~mm}$ i.d. appears to yield inaccurate results.

In combination with microbore columns the method can be used, provided the columns have a maximum length of $5 \mathrm{~cm}$ and contain a packing material with a particle size of 2 or $3 \mu \mathrm{m}$. The error in the determined instrument variance is then of the order of $2 \mu 1^{2}$.

\section{Introduction}

The total variance of a chromatographic peak consists of contributions from the column and from the instrument.
Provided that the column causes a Gaussian elution profile, the contribution from the column, the column variance $\sigma_{c}^{2}$ equals:

$$
\sigma_{c}^{2}=\frac{\left[\left(\pi \cdot r^{2} \cdot L \cdot \epsilon \cdot\left(1+k^{\prime}\right)\right]^{2}\right.}{N}
$$

$r=$ radius of the column

$L=$ length of the column

$\epsilon=$ total porosity

$k^{\prime}=$ capacity factor

$\mathrm{N}=$ plate number

The contribution from outside the column, the instrument variance $\sigma_{\mathrm{A}}^{2}$ equals:

$$
\sigma_{\mathrm{A}}^{2}=\sigma_{1}^{2}+\sigma_{\mathrm{D}}^{2}+\sigma_{\mathrm{N}}^{2}+\sigma_{\mathrm{T}}^{2}
$$

$\sigma_{1}^{2}=$ variance due to volume and geometry of the injector

$\sigma_{D}^{2}=$ variance due to volume and geometry of the detector $\sigma_{N}^{2}=$ variance due to unions, frits and connecting tubes

$\sigma_{T}^{2}=$ variance due to finite speed of response of the electronic circuits of the detector and the recorder.

A commonly accepted criterion for the contribution of the instrument is that this should not exceed $10 \%$ of the column variance. This equals a loss of efficiency of $10 \%$ and a loss of resolution of $5 \%$. Thus

$$
\sigma_{A}^{2} \leqslant 0.1 \sigma_{C}^{2}=\frac{\pi^{2} \cdot r^{4} \cdot L^{2} \cdot \epsilon^{2}\left(1+k^{\prime}\right)^{2}}{N} \cdot 0.1
$$

Using a conventional column, i.e. with an inner diameter of $4.6 \mathrm{~mm}$ and assuming $\epsilon=0.7, N=10.000, L=25 \mathrm{~cm}$ and $k^{\prime}=0$, the extra column variance should not exceed $\left.85 \mu\right|^{2}$. Under identical chromatographic conditions, but using a microbore column with an inner diameter of 1.0 $\mathrm{mm}$, the instrument variance should not exceed $\left.0.2 \mu\right|^{2}$.

When columns with small inner diameters are used special attention should necessarily be given to the magnitude of the instrument variance, because the column variance 
is proportional to the fourth power of the inner diameter of the column.

In chromatographic practice the influence of the equipment on overall performance is underestimated. Accurate methods must be available to determine this contribution to total band broadening.

Instrument variance can be determined in several ways:

1. The column is removed from the chromatographic system and the injector and detector are coupled directly with a low dead volume union, the assumption being that the contribution of the latter to the total variance is negligible. By using this method the measured total variance equals the instrument variance $[1,2]$.

2. The column is replaced by a capillary tube. The instrument variance now equals the observed total variance minus the contribution of the tube, $\sigma_{\text {cap }}^{2}$ [3], calculated from (4):

$\sigma_{\mathrm{A}}^{2}=\sigma_{\mathrm{t}}^{2}-\sigma_{\text {cap }}^{2} ; \sigma_{\text {cap }}^{2}=\frac{\pi \cdot r^{4} \cdot \mathrm{L} \cdot \mathrm{F}}{24 \mathrm{D}_{\mathrm{m}}}$

$D_{m}=$ diffusion coefficient of component in the eluent.

$\mathrm{F}=$ volumetric flow rate of the eluent.

$\sigma_{\mathrm{t}}^{2}=$ observed total variance in (volume) ${ }^{2}$ units.

Repeated measuring of the total variance by using capillary tubes with the same inner diameter but with different lengths constitutes a variant to the latter method. By plotting the total variance versus the length of the capillary tubes in a graph, and by extrapolating this line to length zero, the instrument variance is obtained [4]. In either method, however, the column has to be removed from the chromatographic system. This is a fundamental change and the extra column variance obtained in this way is doubtful for several reasons:

- in both methods the frits are absent,

- in the first method a union is absent,

- the flow profiles normally present at the entrance and the exit of the column have disappeared. As a result of a sudden change in inner diameter and deviating flow behavior [4], these are probably important contributions to the peak dispersion.

- the injection profile of the sample, and by that the peak dispersion, will probably be influenced by the absence of the back pressure from the column in the system.

- these methods have a very short measuring time, as a result of which the contribution of the time constants of the electronics to the instrument variance becomes disproportionally large.

- most HPLC pumps only work accurately when there is a certain back pressure from the system.

It is, therefore, not likely that the instrument variance will be determined accurately by either of these methods. A third method, however, is available to ascertain the instrument variance experimentally. This method, the linear extrapolation method (LEM), has often been used in recent times $[1,3,6,7]$. This is not surprising in view of the objections to the other two methods.
In the LEM, use is made of the additivity of the column variance $\sigma_{C}^{2}$ and the instrument variance $\sigma_{A}^{2}$. Combination with $\mathrm{t}_{\mathrm{R}}=\mathrm{t}_{0}\left(1+\mathrm{k}^{\prime}\right) ; \mathrm{V}_{\mathrm{R}}=\mathrm{t}_{\mathrm{R}} \cdot \mathrm{F}$ and $\mathrm{N}=\left(\mathrm{V}_{\mathrm{R}} / \sigma\right)^{2}$ yields:

$$
\begin{array}{ll}
\sigma_{\mathrm{t}}^{2}=\frac{t_{0}^{2}}{N} F^{2} \cdot\left(1+k^{\prime}\right)^{2}+\sigma_{A}^{2}, & \begin{array}{l}
\text { (volume })^{2} \text { units; } \\
\text { dividing by } F^{2} \text { yield }
\end{array} \\
\sigma_{t, t}^{2}=\frac{t_{0}^{2}}{N} \cdot\left(1+k^{\prime}\right)^{2}+\sigma_{A, t}^{2} & (\text { time })^{2} \text { units }
\end{array}
$$

By plotting the total variance versus $\left(1+k^{\prime}\right)^{2}$ one obtains a straight line graph with slope $t_{0}^{2} / \mathrm{N}$. By subsequently extrapolating this line to retention time zero, the instrument variance is obtained (Fig. 1).

The LEM, however, contains a number of assumptions:

1. The total variance is the sum of the column and the instrument variances. This means that the different contributions to the instrument variance are independent and are also independent of the column variance. Until now there was no reason to doubt these assumptions $[2,5]$.

2. The instrument variance is independent of the capacity factors of the components. If 1 ) is correct, then 2) is also correct.

3. The slope $t_{0}^{2} / N$ is constant, which means all components have the same plate height. However, this is only the case if:

a. all components have the same diffusion coefficients in the mobile phase.

b. all components have the same diffusion coefficients in the stationary phase.

c. the dependency of the plate height on the capacity factor can be neglected.

Authors, who use the LEM, however, do not always consider these three assumptions [6], or suppose that they are correct $[1,2,7]$.

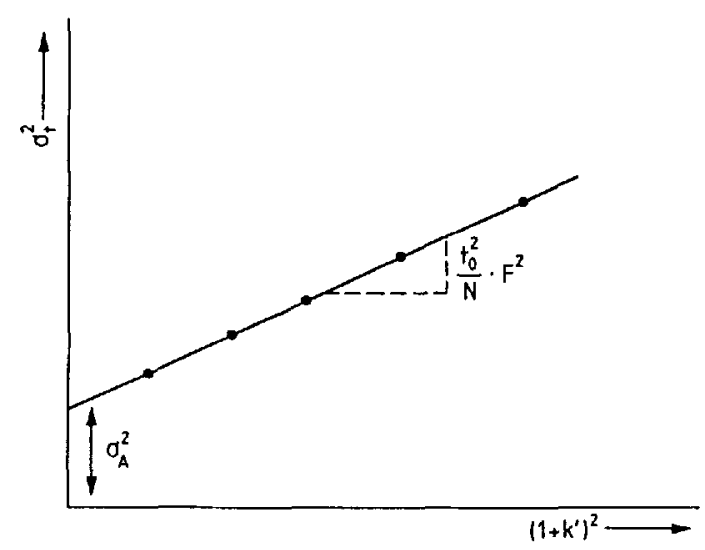

Fig- 1

Schematic preseritation of the linear extrapolation method. 
This is, however, not correct:

ad a/b. By means of the equation of Wilke-Chang [8] it can be shown that even in a homologous series of components not differing much in carbon num. ber, the diffusion coefficients diverge more than $30 \%$, both in the mobile phase and in the stationary pore system.

ad c. By substituting in the plate height equation real values for all parameters, and even assuming that all diffusion coefficients in the mobile phase and in the pores are $10^{-9} \mathrm{~m}^{2} / \mathrm{s}$, the difference in plate height between $k^{\prime}=1.2$ and $k^{\prime}=8.1$ is, depending on the selected linear velocity of the mobile phase, 10 to $20 \%$.

As all three assumptions are not correct, $\mathrm{t}_{0}^{2} / \mathrm{N}$ will not be constant and the intercept with the $\mathrm{Y}$-axis will not be the real instrument variance.

This paper discusses the size of the error which is made by use of the LEM and how this error can be minimized.

\section{Experimental}

A liquid chromatograph (Shimadzu LC-5A microbore chromatographic system, Shimadzu Corp. Japan), equipped with a UV-spectrophotometric detector (SPD-2AM), $0.5 \mu$ l cell volume, variable wavelength type, operating at $254 \mathrm{~nm}$ was used.

The detector output signals were recorded on a Kipp \& Zonen recorder BD 40 (Kipp \& Zonen, Delft, The Netherlands). Microcolumns $250 \times 1.0 \mathrm{~mm}$, packed with reversed phase packing materials, ODS-2, $d p=5 \mu \mathrm{m}$ (Phase Sep., Quensferry, Clwyd, U.K.) were used.

The injection device consisted of a Rheodyne injector with a $0.5 \mu l$ internal loop (Cotati, Cal. USA). The eluent was methanol:water (Merck, Darmstadt, FRG) in the ratio $75: 25(v / v)$.

The test mixture contained benzene, toluene, ethylbenzene, propylbenzene and $n$-butylbenzene, solved in methanol.

\section{Theoretical Considerations. Results}

In order to determine the error in using the LEM, it is necessary to know the actual diffusion coefficients of all components in the mobile and the stationary phase. Also the dependency of the plate height on the capacity factor cannot be neglected. This is possible using real chromatographic data.

While recording the chromatogram care should be taken, that:

1. The difference in dead volume between the total system and the column amounts to no more than a few percent, as otherwise a considerable error will be made in the determination of the capacity factors.

2. The components of the test mixture are a homologous series of molecules which do not differ much in size and show a similar retention behavior then: the diffusion coefficients of the different components do not differ too much; the inaccuracy in the formula of Wilke-Chang is approx. $10 \%$, however, by using this series of solutes possible discrepancies in the calculated diffusion coefficients will be in one direction. It is prevented that as a result of different thermodynamic behaviour of a number of arbitrary components which do not belong to a homologous series, quasi contribute to the instrument variance.

3. The column must be packed perfectly.

It is then possible to calculate for each component of the test mixture the capacity factor $k^{\prime}$, the diffusion coefficient in the mobile phase, $D_{m}$, and the diffusion coefficient in the pores, $D_{p}$ : with $M_{1}=t_{0} \cdot\left(1+k^{\prime}\right)$ the capacity factor is obtained from the chromatogram, where $M_{1}$ is the first moment of the peak, calculated by direct integration; the diffusion coefficient of a component in the mobile phase follows directly from the Wilke-Chang equation:

$$
D=7.4 \cdot 10^{-8} \frac{(X \cdot M)^{1 / 2} \cdot T}{\eta \cdot V^{0.6}}
$$

$D=$ diffusion coefficient of a solute in a solvent $\left(\mathrm{cm}^{2} \mathrm{~s}^{-1}\right)$

$X=$ association parameter

$M=$ molecular weight of the solvent

$\mathrm{T}=$ temperature $\left({ }^{\circ} \mathrm{K}\right)$

$\eta=$ dynamic viscosity of the solvent $(\mathrm{m} . \mathrm{Pa} . \mathrm{s})$

$V=$ molar volume of the solute at normal boiling point $\left(\mathrm{cm}^{3} \mathrm{~mol}^{-1}\right)$

With a mobile phase composition of methanol: water = $75: 25 \mathrm{v} / \mathrm{v}$ and a temperature of $20^{\circ} \mathrm{C}$, the components of the test mixture have the following calculated diffusion coefficients in the mobile phase (Table I).

According to Huber $[9,10]$, the diffusion coefficient of a component in a particle of the packing material $D_{p}$, equals $t \cdot D_{i s}$, where $t$ is the tortuosity factor as a result of the geometry of the porous medium and $D_{\text {is }}$ is the binary diffusion coefficient in the fluid which fills the internal pores. When using pure adsorption chromatography, the flowingand stagnating mobile phases have an identical composition [10] as a result of which $D_{\text {is }}$ equals $D_{m}$. Although in reversed-phase chromatography preferential enrichment occurs, we supposed also for this particular case that $D_{\text {is }}$ equals $D_{m}$.

The relation between the capacity factors of the five components and the diffusion coefficients in the mobile phase and in the pores is thus known. These data can be combined with the plate height equation of Huber [11]:

$$
\begin{aligned}
H= & \frac{2 \lambda_{1} \cdot d_{p}}{1+\lambda_{2} \cdot\left(\frac{\phi \cdot D_{m}}{u \cdot d_{p}}\right)^{1 / 2}}+\frac{2 \gamma_{u} \cdot \phi \cdot D_{m}}{u} \\
& +\frac{1}{3} \cdot \frac{\epsilon}{u}_{1-\epsilon_{u}}^{3 / 2} \cdot\left(\frac{1-\phi+k^{\prime}}{1+k^{\prime}}\right)^{2} \\
& \cdot\left(\frac{d_{p}^{3 / 2} \cdot \nu^{1 / 6}}{\phi^{1 / 2} \cdot D_{m}^{2 / 3}}\right) \cdot u^{1 / 2}+\frac{1}{30} \cdot\left(\frac{1-\epsilon_{u}}{\epsilon_{i}+\epsilon_{s}}\right) \\
& \cdot \frac{\left(1-\phi+k^{\prime}\right)}{\left(1+k^{\prime}\right)^{2}} \cdot \frac{d_{p}^{2}}{D_{p}} \cdot u
\end{aligned}
$$


$\lambda_{1}=$ packing factor $=5$

$\lambda_{2}=$ packing factor $=18$

$\gamma_{\mathrm{u}}=$ labyrinth factor $=0.8$

$\mathrm{t}=$ tortuosity factor $=0.8$

$\epsilon_{\mathrm{u}}=$ volume fraction flowing mobile phase

$\epsilon_{\mathrm{i}}=$ volume fraction stagnating mobile phase

$\epsilon_{\mathrm{s}}=$ volume fraction stationary phase

$d_{p}=$ diameter of the particles of the packing material

$\phi=\epsilon_{\mathrm{u}} / \epsilon_{\mathrm{u}}+\epsilon_{\mathrm{i}}$

$D_{m}=$ diffusion coefficient in the mobile phase

$D_{p}=$ diffusion coefficient in the pores

$\nu=$ linear velocity of the mobile phase

$\mathrm{k}^{\prime}=$ capacity factor

By substituting in the plate height equation not only the determined relations, but also the parameters (volume fractions, $\phi, d_{p}$ ) of the column used, the plate height of the different components can be calculated. This was done for the five components of the test mixture at two different linear velocities of the mobile phase (Table II).

It must be pointed out, that the plate height equation describes only the contributions to the peak dispersion that are caused by the column. At the same linear velocity of the mobile phase, the plate height of the different components is not necessarily equally large. By plotting $\sigma_{t}^{2}$ versus $\left(1+k^{\prime}\right)^{2}$ no straight line will be obtained as a result of which the intercept with the $Y$-axis will not be equal to the variance caused by the instrument. In order to detect the size of the error which the linear extrapolation method yields, the situation will be considered in which the instrument variance is zero.

This means that:

1. The total variance $\sigma_{t}^{2}$ is equal to the column variance $\sigma_{c}^{2}$

2. In applying the LEM by extrapolation to retention time zero, the intersection with the $Y$-axis will coincide with the origin.

By combination of equation (1) $(L=25 \mathrm{~cm}, r=0.5 \mathrm{~mm}$, $\epsilon=0.7)$ with the plate heights that were calculated for the different components (see Table II), five points in the graph of $\sigma_{t}^{2}$ versus $\left(1+k^{\prime}\right)^{2}$ were calculated (Table $\mid I I$ and Fig. 2).

It is now possible, by using the linear least-squares method and extrapolation, to determine to what extent the intersection with the $Y$-axis, i.e. the obtained instrument variance, differs from zero, i.e. the assumed value.

At $u=4 \cdot 10^{-3} \mathrm{~m} / \mathrm{s}$ a straight line with slope $3.40 \mu \mathrm{l}^{2}$ and correlation coefficient 0.9996 is obtained, of which the intersection with the $Y$-axis is at $-\left.9.15 \mu\right|^{2}$. The instrument variance as determined with the linear extrapolation method thus equals $-\left.9.15 \mu\right|^{2}$. However, this variance, as assumed, should equal zero. At $\mathrm{u}=10^{-3} \mathrm{~m} / \mathrm{s}$ a straight line with slope $\left.1.77 \mu\right|^{2}$ and correlation coefficient 0.9998 is obtained, of which the intersection with the $Y$-axis is at $-\left.4.30 \mu\right|^{2}$.

\section{Discussion}

Possible inaccuracy in the data which were substituted in the plate height equation did not essentially change the result. This appears from Table IV, in which for two linear
Table 1. Diffusion coefficients of a homologue series in methanolwater, $75: 25 \mathrm{v} / \mathrm{v}$ at $20^{\circ} \mathrm{C}$, calculated from equation (6).

\begin{tabular}{|ll|}
\hline Benzene & $D_{m}=0.763 \cdot 10^{-5} \mathrm{~cm}^{2} / \mathrm{s}$ \\
Toluene & $D_{m}=0.674 \cdot 10^{-5} \mathrm{~cm}^{2} / \mathrm{s}$ \\
Ethylbenzene & $D_{m}=0.608 \cdot 10^{-5} \mathrm{~cm}^{2} / \mathrm{s}$ \\
Propylbenzene & $D_{m}=0.556 \cdot 10^{-5} \mathrm{~cm}^{2} / \mathrm{s}$ \\
Butylbenzene & $D_{m}=0.515 \cdot 10^{-5} \mathrm{~cm}^{2} / \mathrm{s}$ \\
\hline
\end{tabular}

Table II. Plate heights of the components of a homologue series at two eluent velocities.

\begin{tabular}{|l|c|c|c|}
\hline Component & $\begin{array}{c}\text { Capacity } \\
\text { factor }\end{array}$ & $\begin{array}{c}\text { Plate height }(\mu \mathrm{m}) \\
\mathrm{u}=4 \cdot 10^{-3} \mathrm{~m} / \mathrm{s}\end{array}$ & $\begin{array}{c}\text { Plate height }(\mu \mathrm{m}) \\
\mathrm{u}=10^{-3} \mathrm{~m} / \mathrm{s}\end{array}$ \\
Benzene & 1.25 & 29.7 & 15.6 \\
Toluene & 2.10 & 33.6 & 17.7 \\
Ethylbenzene & 3.13 & 36.8 & 19.4 \\
Propylbenzene & 5.02 & 39.9 & 21.2 \\
Butylbenzene & 8.13 & 43.9 & 22.8 \\
\hline
\end{tabular}

Table III. Relation between the total variance and $\left(1+k^{\prime}\right)^{2}$.

\begin{tabular}{|l|c|c|c|}
\hline & $\left(1+k^{\prime}\right)^{2}$ & $\begin{array}{c}\sigma_{\mathrm{t}}^{2}\left\langle\left.\mu\right|^{2}\right) \\
\mathrm{u}=4 \cdot 10^{-3} \mathrm{~m} / \mathrm{s}\end{array}$ & $\begin{array}{c}\sigma_{\mathrm{t}}^{2}\left(\left.\mu\right|^{2}\right) \\
\mathrm{u}=10^{-3} \mathrm{~m} / \mathrm{s}\end{array}$ \\
\hline Benzene & 5.05 & 11.32 & 5.96 \\
Toluene & 9.60 & 24.38 & 12.86 \\
Ethylbenzene & 17.03 & 47.43 & 25.08 \\
Propylbenzene & 36.19 & 105.21 & 58.06 \\
Butylbenzene & 83.30 & 276.52 & 143.58 \\
\hline
\end{tabular}

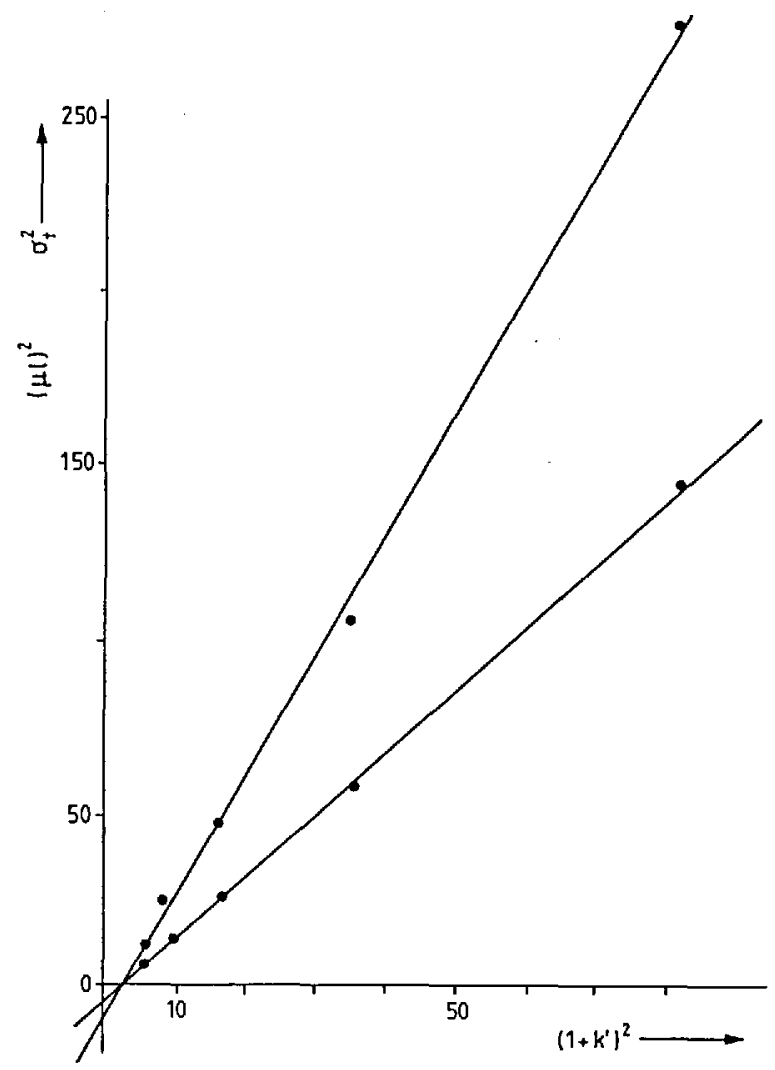

Fig. 2

Total calculated variance versus $\left(1+k^{\prime}\right)^{2}$ at two linear velocities of the eluent. 
velocities of the mobile phase, both the calculated quasiinstrument variances and the influence from inaccuracies in the calculated plate height, are shown.

The linear least-squares method is used in the determination of the straight line which best fits the experimental points. It is concluded from the value of the correlation coefficient that the calculated line corresponds well with the data points. However, to obtain more certainty, a statistical program based on the "Student's" $t$ distribution, was used. By means of this program it was possible to determine the boundaries of the area in which the lines are situated that describe the measuring points with a reliability of at least $95 \%$. These boundaries, the so-called inclusion curves, are shown in Fig. 3 for the situation at which $\mathrm{u}=4 \cdot 10^{-3} \mathrm{~ms}^{-1}$ and $\mathrm{H}=$ calculated $\mathrm{H}$.

The intersection with the $Y$-axis appears to be between -16.8 and $-1.5 \mu 1^{2}$ with a reliability of $95 \%$.

Table $V$ shows four cases in which values, between which the intersection with the $Y$-axis should be, have been determined, by means of inclusion curves.

Tables IV and $V$ show that, when using the LEM and this microbore column, the determined instrument variance is 1 to $20 \mu 1^{2}$ too small.

Assuming that the plate height equation is independent of the length and diameter of the column, and under the same chromatographic conditions, it can be shown from formula (1), that reducing the column length and/or diameter reduces the column variance and thus the error in the estimated instrument variance. Reducing the diameter of the column, however, means that the flowing profiles at the column ends are changed which is, as was pointed out before, not desirable. Reducing the length of the column is possible without influencing the system. A reduction of the length of the column from 25 to $5 \mathrm{~cm}$ means that the error in the measured instrument variance will be $\left.4 \mu\right|^{2}$. By using packing material with a particle size of 2 or $3 \mu \mathrm{m}$ this value can be reduced to $2 \mu l^{2}$. In view of the present state-of-the-art this is for the time being an acceptable error $[3,6,12]$. An additional advantage in this case is that the pressure drop is significant.

For conventional columns with an inner diameter of $4.6 \mathrm{~mm}$, it can be concluded that under identical chromatographic conditions, the error in the measured instrument variance is 448 times larger than with microbore systems.

Even when the conventional column has a length of $5 \mathrm{~cm}$, it is possible that the error in the experimentally obtained instrument variance is about $1800 \mu l^{2}$. This value is unacceptably large, even for a conventional HPLC system.

\section{Conclusions}

The linear extrapolation method is only correct when a number of assumptions are met. Three of the assumptions are positively not true. This implies that the instrument variance determined with the linear extrapolation method is not correct.

With conventional columns with a length of $25 \mathrm{~cm}$, the error which is made in using the LEM is at least a few

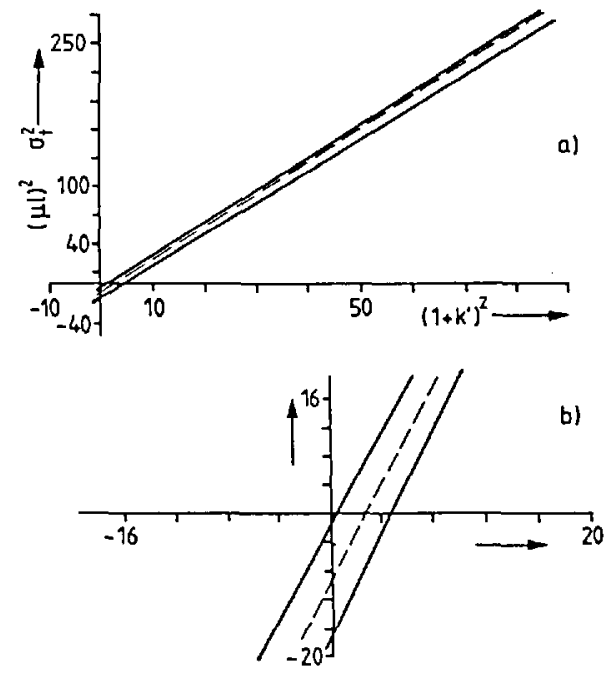

Fig. 3

a) Inclusion curves with a reliability criterion of $95 \%\left(u=4 \cdot 10^{-3}\right.$ $\mathrm{m} / \mathrm{s}$, calculated $H$ ).

b) Enlargement of the area around the origin.

$\longrightarrow$ inclusion curves

$----n=$ experimental curve

Table IV. Quasi-instrument variances obtained with the linear extrapolation method.

\begin{tabular}{|c|c|c|c|c|}
\hline & \multicolumn{2}{|c|}{$\mathrm{u}=4 \cdot 10^{-3} \mathrm{~m} / \mathrm{s}$} & \multicolumn{2}{|c|}{$u=10^{-3} \mathrm{~m} / \mathrm{s}$} \\
\hline & $\begin{array}{c}\text { quasi } \\
\sigma_{A}^{2} \\
(\mu \mid)^{2}\end{array}$ & $\begin{array}{l}\text { correlation } \\
\text { coefficient }\end{array}$ & $\begin{array}{c}\text { quasi } \\
\sigma_{A}^{2} \\
\langle\mu|)^{2}\end{array}$ & $\begin{array}{l}\text { correlation } \\
\text { coefficient }\end{array}$ \\
\hline Calculated H & -9.15 & 0.9996 & -4.30 & 0.9998 \\
\hline $\mathrm{H}$ is $10 \%$ larger & -10.07 & 0.9996 & -4.73 & 0.9998 \\
\hline $\mathrm{H}$ is $20 \%$ larger & -10.98 & 0.9996 & -5.16 & 0.9998 \\
\hline $\mathrm{H}$ is $30 \%$ larger & -11.89 & 0.9996 & -5.59 & 0.9998 \\
\hline $\mathrm{H}$ is $10 \%$ smaller & -8.23 & 0.9996 & -3.87 & 0.9998 \\
\hline $\mathrm{H}$ is $20 \%$ smaller & $-\quad 7.32$ & 0.9996 & -3.44 & 0.9998 \\
\hline $\mathrm{H}$ is $30 \%$ smaller & -6.40 & 0.9996 & -3.01 & 0.9998 \\
\hline
\end{tabular}

Table V. Maximum and minimum quasi-instrument variances determined by the use of inclusion curves (reliability $95 \%$ ).

\begin{tabular}{|l|c|c|}
\hline & $\begin{array}{c}\text { Maximum } \\
\text { quasi } \\
\sigma_{\AA}^{2}(\mu \mid)^{2}\end{array}$ & $\begin{array}{c}\text { Minimum } \\
\text { quasi } \\
\sigma_{\AA}^{2}(\mu \mid)^{2}\end{array}$ \\
\hline $\mathrm{u}=4 \cdot 10^{-3} \mathrm{~m} / \mathrm{s} ;$ calculated $\mathrm{H}$ & -1.5 & -16.8 \\
$\mathrm{u}=4 \cdot 10^{-3} \mathrm{~m} / \mathrm{s} ; \mathrm{H} 20 \%$ larger & -1.7 & -20.2 \\
$\mathrm{u}=4 \cdot 10^{-3} \mathrm{~m} / \mathrm{s} ; \mathrm{H} 20 \%$ smaller & -1.2 & -13.5 \\
$\mathrm{u}=10^{-3} \mathrm{~m} / \mathrm{s}$; calculated $\mathrm{H}$ & -1.5 & -7.1 \\
\hline
\end{tabular}

hundred $\mu 1^{2}$ and at most a few thousand $\left.\mu\right|^{2}$. This means that it is not possible to use the LEM in combination with conventional columns.

With microbore columns with a length of $2 b \mathrm{~cm}$ the instrument variance determined with the LEM is at most $\left.20 \mu\right|^{2}$ too small. By reducing the length of the microbore column to $5 \mathrm{~cm}$, the maximum error is reduced to $4 \mu \mathrm{l}^{2}$. By 
using packing material with a particle size of 2 or $3 \mu \mathrm{m}$ this value can be reduced to about $2 \mu l^{2}$.

Provided that a number of conditions are met, the LEM is an accurate method to determine the instrument variance.

\section{Acknowledgement}

The authors gratefully acknowledge Pleuger N.V., Wijnegem, Belgium and Lamers-Pleuger, 's-Hertogenbosch, The Netherlands, for putting the HPLC equipment at our disposal.

We thank Mrs. A.A.J. Rosenbrand for revising the manuscript and Mrs. D. C. M. Tjallema for her technical assistance.

\section{References}

[1] H. H. Lauer, G.P. Rozing, Chromatographia 19, 641 (1981).

[2] K.H. Hupe, R.J. Jonker, G. Rozing, J. Chromatogr., 285. $253(1984)$.

[3] K.W. Freebairn, J. H. Knox, Chromatographia 19, 37 (1984).

[4] J.J. Kirkland, W.W. Yau, H.J.Stoklosa, C. H. Dilks jr., J. Chromatogr. Sci., 15, 303 (1977).

[5] J.C. Sternberg, Advances in Chromatography, Vol. 2, J.C. Giddings, R.A. Keller, Eds., Marcel Dekker, New York, 205-270 (1966).

[6] P.J. Naish, D.P. Goulder, C. V. Perkins, Chromatographia $20,335(1985)$.

[7] W.Th. Kok, U. A. Th. Brinkman, R. W. Frei, H. B. Hanekamp, F. Nooitgedacht, H. Poppe, J. Chromatogr., 237, 357 (1982).

[8] C. R. Wilke, P. Chang, A. I. Ch. E. Journal, 1, 264 (1955).

[9] J.F. K. Huber, J. Chromatogr. Sci., 7, 85 (1969).

[10] J.F. K. Huber, Ber. Bunsenges. Phys. Chem., 77, 179 (1973).

[11] R.S. Deelder, P. H. Tomassen, J. H. M. van den Berg, Chromatografie, Ed., Elsevier Science Publ., Amsterdam (1985).

[12] J.H.M. van den Berg, H.W.M. Horsels, R.J.M. Groenen, Chromatographia 18, 574 (1984).

Received: Dec. 19, 1986 Accepted: Jan. 28, 1987 